\title{
A normalidade gay e a transformação queer ${ }^{1}$
}

Peter Drucker ${ }^{2}$

Resumo: Nos últimos 50 anos, as vitórias dos movimentos LGBTI foram reais e importantes, mas estiveram, ao mesmo tempo, entrelaçadas às derrotas significativas. Onde os movimentos aparentemente obtiveram maiores ganhos, as vidas LGBTI foram circunscritas a uma nova "homonormatividade" ligada ao neoliberalismo. Cinco traços homonormativos definem uma nova formação hegemônica entre o mesmo sexo: a autodefinição da comunidade lésbica/gay como uma minoria estável, o aumento da conformidade de gênero, a marginalização das pessoas trans, a maior integração à nação e a formação de famílias lésbicas/gays normalizadas. Ao mesmo tempo, muitos queers estão rejeitando o consumismo, a respeitabilidade e a conformidade e, portanto, a normalidade gay. Não obstante, é apenas lentamente que a resistência queer à homonormatividade desenvolve a teoria de que necessita, incluindo um marxismo feminista, não eurocêntrico e anti-economicista. Para alcançar uma liberação completa, uma política queer tem que "queerizar" os movimentos sociais de classe e radicalizar sua investida contra o binarismo gay/hétero. Isto significa lutar por uma vida erótica que é polimorficamente sensual, e não genitalmente obcecada; igualitária e não possessiva.

Palavras-chave: Homonormatividade; queer; neoliberalismo.

Abstract: LGBTI movements' victories over the past fifty years have been both real and important, and enmeshed in significant defeats.

\footnotetext{
1 Em versão estendida, este artigo foi publicado originalmente em Zapruder World, vol. 2, junho de 2015. A adequação do texto para o Cadernos Cemarx foi feita pelo próprio autor. Tradução: Murillo van der Laan. Revisão: Mariana Shinohara Roncato e Rafael Dias Toitio.

${ }^{2}$ Pesquisador do International Institute for Research and Education, Amsterdã. E-mail: polias@antenna.nl.
} 
Where the movements have seemingly won most, LGBTI lives are circumscribed by a new 'homonormativity' linked to neoliberalism. Five homonormative features define a newly hegemonic same-sex formation: the lesbian/gay community's self-definition as a stable minority, increasing gender conformity, marginalisation of trans people, increasing integration into the nation, and the formation of normalised lesbian/gay families. At the same time, many queers are rejecting overconsumption, respectability and conformity, and thus gay normality. Yet queer resistance to homonormativity is only slowly developing the theory it needs, including a feminist, non-Eurocentrist and anti-economistic Marxism. To achieve full liberation, a queer politics has to both 'queer' class-based and other social movements and radicalise its assault on the gay/straight binary. This means fighting for an erotic life that is polymorphously sensual rather than genitally obsessed, egalitarian rather than possessive.

Keywords: Homonormativity; queer; neoliberalism.

Nos últimos 50 anos, os movimentos de lésbicas/gays/bissexuais/ transgêneros/intersexos (LGBTI) em boa parte do mundo obtiveram uma série de vitórias. Em 2011, o Conselho de Direitos Humanos das Nações Unidas aprovou, por maioria de votos, a proteção às minorias sexuais. $\mathrm{O}$ direito ao casamento entre pessoas do mesmo sexo não foi apenas conquistado na África do Sul, Argentina e nos Estados Unidos, mas também tem sido considerado no Nepal e no Vietnã. Como John D'Emilio afirmou, a partir dos anos 1990, “o mundo virou” para milhões de pessoas LGBTI (D’EMILIO, 2002, p. ix).

Ainda assim, muitos ativistas LGBTI não estão inteiramente felizes com o mundo que conquistaram³. Há recorrentes backlashes em países como Uganda e Nigéria. A oposição ao casamento entre pessoas do mesmo sexo explodiu na França em 2013, mostrando o quanto o preconceito contra gays ainda está à espreita abaixo da superfície. $\mathrm{E}$ as reações negativas não são os únicos problemas. Mesmo quando

${ }^{3}$ Tomo essa frase emprestada de Weeks, 2007.

198 A normalidade gay e a transformação... 
o movimento não apenas ganha, mas mantém suas vitórias, a forma que estas assumem é perturbadora. Poucos ativistas gays em 1969 aceitariam o uso de argumentos a favor da liberdade sexual como justificativa para guerras na Ásia Ocidental e para o preconceito contra muçulmanos, ou o uso de uniões civis entre pessoas do mesmo sexo para o planejamento imobiliário e fiscal de casais ricos do mesmo sexo.

As vitórias das pessoas LGBTI são reais e importantes, mas se entrelaçam, ao mesmo tempo, às derrotas expressivas. Por terem sido conquistadas em um mundo crescentemente desigual, polarizado e violento, elas assumiram uma coloração perturbadora. A liberdade que gozam as pessoas LGBTI é cada vez mais dependente de um mercado que é sobretudo acolhedor para pessoas com dinheiro. Os resultados são uma crescente comercialização da cena gay e um desvio à direita dos movimentos LGBTI.

Em países onde os movimentos parecem ter sido mais bem sucedidos, as vidas LGBTI estão cada vez mais circunscritas por uma política de reconciliação com o neoliberalismo, que Lisa Duggan (2002) chamou de "nova homonormatividade": uma mentalidade que não "contesta as suposições e instituições heteronormativas dominantes, mas que as apoia e sustenta". Ao mesmo tempo, a crescente desigualdade racial subjacente a um multiculturalismo superficial alimenta ondas de reações anti-LGBTI no mundo Islâmico e na África, e entre outros que são racializados.

Éapenaslentamentequea resistênciaqueeràhomonormatividade está desenvolvendo a teoria que necessita para guiá-la, incluindo a adoção de um tipo específico de marxismo: não reducionista, não eurocêntrico e anti-economicista, e fundado no imperativo básico da auto-organização de todos os oprimidos. Os queers precisam, especialmente, adotar o feminismo socialista que entende o capitalismo, em sua essência, como um modo social de produção e reprodução generificada [gendered]. Nós também precisamos integrar ao marxismo insights fundamentais advindos de outros paradigmas: o freudismo radical impulsionado por Herbert Marcuse, o libertarismo 
de Michel Foucault, e o ativismo queer ligado, em certa medida, à recente teoria queer.

A força singular do marxismo está em sua compreensão das dinâmicas do capitalismo, e do papel-chave que a classe trabalhadora pode desempenhar para resistir ao poder do capital. A experiência histórica - não apenas na Rússia de 1917 e na França de 1968, mas também no papel mais recente do trabalho na deposição das ditaduras, do Brasil à Polônia, da Coréia do Sul à Tunísia, e outros países - demonstrou o potencial revolucionário da classe trabalhadora. Mas a reivindicação especial do marxismo por atenção dos ativistas LGBTI depende de sua efetividade em criar uma análise e uma política sexual multidimensional que aborde o nacionalismo, a raça e o gênero, assim como a classe e o capital. A reinvenção da política de classes voltada à transformação anticapitalista apenas pode ocorrer em interação com correntes não baseadas na classe, como a queer.

Este artigo tem o intuito de contribuir com uma política queer de transformação anticapitalista. Sua primeira seção situa a liberação lésbica/gay, de 1968 à 1973, no interior da história mais ampla das sexualidades entre pessoas do mesmo sexo. A segunda seção analisa como, por volta dos anos 1990, a normalidade gay, quase imperceptivelmente, esmagou o potencial dos libertadores lésbicos/gays. Esta seção esboça cinco características do novo padrão hegemônico da normalidade gay: a autodefinição da comunidade lésbica/gay como uma minoria estável, uma crescente conformidade de gênero, a marginalização das pessoas trans e de outras minorias no interior da minoria, a cada vez maior integração à nação, e a formação de novas famílias lésbicas/gays normalizadas.

Ainda assim, o mesmo período neoliberal tem testemunhado o crescimento de uma cena queer alternativa, cujos proponentes rejeitam o consumo excessivo, a respeitabilidade e a conformidade e, portanto, a normalidade gay. A terceira seção do artigo argumenta que graças à resistência queer, ainda existe o potencial de conectar a transformação sexual e social através do aprofundamento de um nascente programa

200 A normalidade gay e a transformação... 
que busca embaralhar as fronteiras sexuais, subvertendo o gênero e defendendo a liberação trans, a solidariedade global e antirracista e o poliamor. O artigo conclui com um chamado para "queerizar" o futuro, através da criação das condições para uma vida erótica que seja polimorficamente sensual e não genitalmente obcecada; igualitária, ao invés de possessiva.

\section{8-1973: um parêntese revolucionário}

A normalidade gay dos dias de hoje está alinhada com a "homossexualidade" da forma como foi inventada no final do século XIX. Mas ela representa uma ruptura com a liberação do final dos anos 1960 e começo dos anos 1970. A liberação lésbica/gay foi, de fato, uma rebelião contra a homossexualidade de seu tempo.

A identidade homossexual que tomou forma nas décadas seguintes à Segunda Guerra Mundial era uma nova variante da perspectiva binária hetero/homo. Nas relações de mesmo sexo formadas sobre esse padrão - diferentemente de formas de "inversão sexual" mais antigas - nenhum dos parceiros mudava radicalmente sua identidade de gênero ou papel sexual, e ambos consideravam-se parte da mesma comunidade. As bases dessa nova identidade gay foram estabelecidas em partes da Europa ocidental e da América Latina e do Norte nas duas décadas após a Segunda Guerra Mundial através da expansão da cena comercial lésbica/homossexual e dos esforços de pequenos grupos "homofílicos".

Mas a grande reviravolta para a identidade lésbica/gay nos anos pós-1968 foi, em certa medida, a ruptura com a normatividade de gênero, especialmente com a identidade homossexual da classe média, que grupos homofílicos dos anos 1950 ajudaram a consolidar. A liberação lésbica/gay foi inspirada por uma visão que, ao menos por alguns anos, incluía drag queens, hustlers e outras perspectivas sexuais legalmente proscritas. Tal reviravolta também inspirouse conscientemente no feminismo de esquerda e nas lutas anti- 
imperialistas. Começando com o Maio de 1968 na França, a esquerda passou a ter um papel proeminente no movimento lésbico/gay, através de coletivos e de publicações em cidades como Londres, Los Angeles, Nova Iorque, Boston, Toronto e São Paulo. Para esta reviravolta, também foi importante a crescente revolta de drag queens e de gigolôs. A revolta de Stonewall em Nova Iorque, em 1969, um momento crucial da liberação lésbica/gay, continuava uma série de revoltas trans nos Estados Unidos, começando com a do Cooper's Donuts ${ }^{4}$, em 1959 (STRYKER, 2008, p. 53-55, p. 59-65). As décadas de lutas que se seguiram levaram a vitórias - especialmente leis contra discriminação - que tornaram possíveis, pela primeira vez, comunidades lésbicas/ gays massivas e abertas.

As lésbicas desempenharam um papel fundamental e visível no crescente movimento feminista socialista. As lésbicas feministas compreendiam facilmente que liberdade e igualdade para lésbicas demandavam a emancipação das mulheres, de maneira que estas tivessem opções outras além do casamento e da dependência econômica dos homens. Ativistas lésbicas/gays lutavam por um mundo no qual as mulheres teriam tanto poder quanto os homens, fossem tão fortes quanto eles, e tivessem um papel de igual dimensão na vida pública, e para que os homens fossem tão gentis e emotivos quanto as mulheres, e assumissem um papel igualitário no lar, tornando-se também tão cuidadores das crianças quanto elas.

Em tal mundo, uma preferência fixa por um parceiro masculino ou feminino não seria nem mais normal ou mais estranho do que uma preferência fixa por loiras. Allen Young da Gay Liberation Front demandava "um fim para a programação de gênero que começa quando nascemos" e declarava que "em uma sociedade livre todo mundo será gay" (D’EMILIO e FREEDMAN, 1997, p. 321-322) -

${ }^{4}$ O Cooper's Donuts era um estabelecimento de Los Angeles receptivo à comunidade trans. Em 1959, a intimidação de policiais que exigiram a identificação de alguns de seus frequentadores detonou a revolta dos clientes transgêneros e homossexuais. [N.T.]

202 A normalidade gay e a transformação... 
isto é, transcenderia as categorias de heterossexual e homossexual. A liberação lésbica/gay rejeitava um grupo modelo minoritário em favor de uma visão universal de liberação sexual.

\section{Neoliberalismo e a normalidade gay}

Em meados dos anos 1970, entretanto, os anti-machos, em grande medida, perderam terreno entre os ativistas gays. O movimento começou a marginalizar e excluir os dissidentes de gênero. Hoje, as vidas LGBTI e as lutas têm de ser situadas no contexto do neoliberalismo, o período específico do capitalismo no qual o mundo se encontra por mais de trinta anos.

As décadas de privatização neoliberal e de desregulamentação foram também as décadas do que Alan Sears chamou de "desregulamentação moral", quando algumas restrições sexuais que atuavam como barreiras à acumulação do capital foram removidas. Isto facilitou a proliferação de boates, bares, saunas (para homens gays e bissexuais), publicações, chats, etc. LGBTs. Novos nichos de mercado gays e lésbicos se tornaram o centro dinâmico de espaços nos quais homens e mulheres pudessem explorar, exercer e celebrar seus desejos pelo mesmo sexo.

No entanto, a desregulamentação moral neoliberal não apenas expandiu as possibilidades sexuais, mas também promoveu novos tipos de conformismo. $\mathrm{O}$ mundo comercial gay pode ser grande, mas não é nenhum modelo de diversidade. A despeito da possibilidade de se lucrar nos nichos LGBTI de mercado, ganha-se muito mais nos espaços uniformes que focam nos consumidores com a demanda mais efetiva, onde pessoas com os corpos errados, com as roupas erradas, com as práticas sexuais erradas, com o gênero errado ou com a cor da pele errada são vistas como ruins para o marketing e são frequentemente excluídas. O crescimento da cena comercial tem, portanto, aumentado o estigma e a marginalização de muitas pessoas LGBTI. 
Em uma economia de maior desigualdade, ademais, a participação em uma cena comercializada demanda a capacidade de pagar. E mesmo quando os estabelecimentos comerciais servem como espaços para comportamentos percebidos como transgressores, a ousadia sexual é frequentemente confinada à "vida privada" e ao "tempo livre". Atitudes que podem ser admiradas em uma boate no sábado à noite, podem significar problemas no trabalho ou em muitas ruas da cidade na segunda de manhã. Mesmo pessoas que "saíram do armário", no trabalho e em público, geralmente autoguetizam todos os tipos de atitudes e imagens que são centrais para sua identidade LGBTI. A emergência de camadas pequeno-burguesas fomentou a propagação de vidas gays relativamente confortáveis, normalizadas, em um canto tolerado do mundo heteronormativo.

Essa nova ordem homonormativa encaixa-se dentro de uma ordem de gênero na qual a dominação direta masculina da mulher é camuflada em instituições aparentemente neutras ao gênero. A instituição do casamento também foi remodelada. O Estado ainda usa o status marital para canalizar muitos benefícios a casais, especialmente aos mais prósperos, como seguro de vida e isenções de impostos sobre herança e ganhos de capital. Por outro lado, quando se trata de proteção social e benefícios aos desempregados, o Estado neoliberal desvia-se cada vez mais de suas responsabilidades penalizando os casais - algumas vezes casados, outras vezes todos os casais, mas sempre atingindo desproporcionalmente as pessoas da classe trabalhadora, de baixa renda e pobres.

Sob o neoliberalismo, formas de heteronormatividade mudaram de maneiras diferentes entre as classes. A expansão do mercado tem sido uma boa notícia para algumas pessoas LGBTI. O desconforto da diferença - em uma sociedade onde o desejo exclusivamente heterossexual é a norma - foi atenuado entre algumas camadas superiores de trabalhadores e da classe média que prosperaram nos anos 1980 e 1990, não apenas nos países imperialistas, mas também em partes da América Latina, da África do Sul e do Leste e Sul da Ásia. Cinco traços homonormativos definiram uma nova formação

204 A normalidade gay e a transformação... 
hegemônica de mesmo sexo: a autodefinição da comunidade lésbica/gay como uma minoria estável; uma tendência crescente à conformidade de gênero; a demarcação e marginalização das pessoas trans e de outras minorias dentro da minoria; a integração crescente à nação; e a formação de novas famílias lésbicas/gays normalizadas.

A auto-definição de lésbicas e de homens gays como uma minoria formou-se sobre uma consolidação regular das categorias de gay e hétero ao longo do século XX. À medida em que lésbicas e gays foram cada vez mais definidos como pessoas que habitam certo espaço econômico (vão a certos bares, saunas, boates e são clientes de determinados negócios), foram mais guetizados do que antes, mais claramente demarcados frente a uma maioria definida como hétero.

O declínio dos papéis de butch/femme ${ }^{5}$ entre lésbicas e da cultura Camp ${ }^{6}$ entre homens gays também ajudou a enrijecer as fronteiras. Drag queens que desempenharam um papel de liderança nos levantes dos anos 1960, descobriram a partir da década de 1970 que, enquanto em seu conjunto aumentava a tolerância à lésbicas e gays, a tolerância à não conformidade de gênero em muitos espaços lésbicos/gays diminuía. Com o declínio do fordismo exercendo pressão sobre os programas estatais, uma ênfase renovada na centralidade da família colocava um freio no afrouxamento das normas de gênero que caracterizou os anos 1960. Este giro conservador na sociedade foi acompanhado por um afastamento de homens gays da androginia e do gender bending ${ }^{7}$ casual dos anos 1970.

\footnotetext{
${ }^{5}$ Butch/femme são termos utilizados para designar identidades masculinas (butch) ou femininas (femme) às lésbicas, a partir de comportamentos, estilos, roupas, adereços, etc. [N.T.]

${ }^{6}$ A cultura camp refere-se a um tipo jocoso de estética, comportamento, interpretação, performance, etc. geralmente associados ao "cafona" ou "brega", ao excesso, à ostentação ou exagero como os que são encontrados, por exemplo, nas atuações das drags queen. [N.T.]

${ }^{7}$ Gender-bending refere-se às práticas que rompem com o binarismo dos papéis de gênero socialmente impostos, através de vestimentas, adereços, comportamentos, etc. [N.T.]
} 
$\mathrm{Na}$ medicina, uma disposição maior para aceitar a homossexualidade como não intrinsecamente patológica foi acompanhada de um foco mais acentuado na não conformidade de gênero, distinguindo e isolando pessoas trans de gays. A patologização das pessoas trans logo se expandiu quando a edição de 1980 da Diagnostic and Statistic Manual of Mental Disorders, da Associação Americana de Psiquiatria - a primeira a aparecer desde a edição de 1973, que havia retirado a homossexualidade da lista - adicionou a nova categoria de Transtorno de Identidade de Gênero. As comunidades lésbicas/gays definiram-se crescentemente de maneiras que colocavam pessoas trans e outras não conformistas nas margens. Nos anos 1990 as identidades trans distintas das lésbicas/gays tornaram-se generalizadas.

Ao lado da demarcação enquanto minoria estável, da crescente conformidade de gênero e da separação entre gays e trans, uma quarta característica da nova normalidade gay tem sido a incorporação de algumas lésbicas e homens gays à nação imperialista. Em uma ordem imperialista, a identidade de gênero e a sexualidade estão intimamente relacionadas, especialmente para os homens. A masculinidade tem sido definida, por séculos, por uma propensão para a violência, valorada positivamente, seja no âmbito militar ou, em uma forma sublimada, no esporte. A incompetência para lutar e para o esporte e a exclusão militar foram, portanto, marcadores de homens insuficientemente masculinos - enquanto carreiras atléticas e militares eram marcadores de mulheres insuficientemente femininas. A exclusão do exército tem sido frequentemente uma das últimas formas de discriminação a cair. Foi explicitamente reafirmada, por exemplo, quando a homossexualidade foi descriminalizada na Grã-Bretanha em 1967 (e revogada apenas no ano 2000), e perpetuada com a política "não pergunte, não conte" do presidente Bill Clinton, adotada em 1993 e revogada em 2011.

A demanda para eliminar do âmbito militar a discriminação baseada na orientação sexual tem sido um elemento constituinte de

206 A normalidade gay e a transformação... 
uma nova homonormatividade nacionalista. Isto tem sido particularmente evidente em Israel, onde a inclusão de homens judeus gays no exército foi um marcador de sua incorporação no projeto sionista - compreensivelmente visto sem qualquer entusiasmo por queers palestinos. De maneira geral, no século XXI, o "homonacionalismo" (para usar o termo de Jasbir Puar) instrumentaliza os direitos lésbicos/gays colocando-os a serviço de ideologias imperialistas e antimuçulmanas (PUAR, 2007, p. xxiv, 38-39). Em países como a Holanda e a Dinamarca, onde tanto os direitos voltados a casais do mesmo sexo quanto o racismo anti-imigração estão fortemente desenvolvidos, esse homonacionalismo tem sido fundamental para domesticar a identidade lésbica/gay. Os Estados Unidos também têm visto o crescimento de uma direita gay homonacionalista. A orgia generalizada de patriotismo nos Estados Unidos, depois do 11 de setembro, também repercutiu entre comunidades LGBTI: "a bandeira Americana apareceu em todos os lugares, em espaços gays, em bares gays, em academias gays e paradas do orgulho gay" (PUAR, 2007, p. 40-43).

Uma quinta, e cada vez mais central, característica definidora da nova normalidade gay é o papel do casamento entre pessoas do mesmo sexo. Os cortes neoliberais dos serviços sociais, ao privatizar a provisão de necessidades básicas, tem restaurado - de maneira classista - a centralidade da unidade familiar na reprodução social do trabalho. Enquanto os direitos de casar e adotar crianças trazem benefícios cruciais práticos e imediatos a casais do mesmo sexo de diferentes classes, eles podem culminar na integração de algumas pessoas gays à ordem produtiva e reprodutiva do capitalismo generificado. A luta por tais direitos é uma demanda por igualdade, mas também, em alguns casos, por privilégios iguais de classe e raça. Um estudo canadense mostrou que o reconhecimento legal de uniões de mesmo sexo, em média, resultou em maiores rendimentos para pessoas LGBTI de alta renda e menores para aquelas de baixa 
renda (BARKER, 2012, p. 100). O reconhecimento estatal de casais do mesmo sexo produz novas formas de exclusão: em países como a Grã-Bretanha, a Alemanha e a Holanda, o reconhecimento legal de uniões de pessoas do mesmo sexo pode levar a cortes de benefícios sociais (BROWNE, 2011; WOLTERSDORFF, 2011, p. 177).

O impacto antissocial do neoliberalismo tem dado a algumas pessoas LGBTI razão para questionarem a normalidade gay. De fato, os casais prósperos que recebem atenção de revistas lésbicas/gays requintadas nunca foram as pessoas LGBTI típicas. Um estudo recente nos Estados Unidos mostrou que, em 2013, 39\% dos LGBTI adultos tinham rendas abaixo de US\$30.000, comparados a $28 \%$ dos adultos em geral (PEW RESEARCH CENTER, 2013). As pessoas trans estão em situação ainda pior: um estudo de 2006 descobriu que em São Francisco $60 \%$ delas ganhavam menos de US\$ 15.300 por ano, apenas $25 \%$ tinham empregos em tempo integral e, aproximadamente, $9 \%$ não tinha nenhuma fonte de renda (WOLF, 2009, p. 147). Entre as pessoas LGBTI menos privilegiadas, o afastamento da cena comercial gay tem crescido rapidamente. Cenas alternativas tem proliferado.

No interior de algumas dessas cenas alternativas, uma identidade queer tem aglutinado aquilo que parece, ao menos em parte, estar em oposição à homonormatividade. A cena queer atravessa divisões de classes: pessoas de classe média que se auto-identificam como queers incluem um número desproporcional de estudantes e acadêmicos. Mas a atmosfera de classe da cena queer, se não é exatamente da classe trabalhadora, é diferente daquela da cena comercial. A predominante rejeição queer ao consumismo, à respeitabilidade e à conformidade colocam as queers em oposição à normalidade gay neoliberal. $\mathrm{E}$ os espaços queer dão mais lugar, ou pelo menos oferecem solidariedade, às pessoas LGBTI que sofreram com os impactos do neoliberalismo.

Militantes trans em grande parte da América Latina e no Sudeste e Sul da Ásia, por exemplo, tem se tornado cada vez mais visíveis

208 A normalidade gay e a transformação... 
e expressivas. As contradições de gênero e de poder têm sido, desde os anos 1990, particularmente visíveis nas subculturas transgêneras e de gender bending. Jovens trans - que cada vez mais se denominam gender queers - são mais propensos a assumirem identidades de gênero que não são nem femininas ou masculinas. Trans que se identificam como queers não necessariamente rejeitam tratamentos hormonais ou cirurgias, por exemplo, mas elas podem ser seletivas sobre o que escolhem ou não escolhem para si mesmas. Os resultados podem ser corpos "'intermediários' em algum lugar entre o feminino e o masculino" (RUBIN, 2011, p. 251).

\section{A transformação Queer}

A atual crise do capitalismo pode ser usada, e está sendo usada, para restaurar uma dimensão utópica na política LGBTI. Não obstante, uma alternativa queer anticapitalista ainda mal começou a tomar forma. Mesmo hoje, com o capitalismo neoliberal claramente em crise, as organizações LGBTI raramente constroem laços fortes com o movimento de trabalhadores ou a esquerda política. Dificilmente poderia se esperar algo nesse sentido enquanto globalmente a esquerda e os trabalhadores estão em profunda desordem.

Felizmente, instintos básicos de raça e classe ainda imunizam muitos LGBTIs contra a direita gay. A maioria é da classe trabalhadora - no sentido amplo de ter de trabalhar para um empregador para sobreviver - e muitos se rebelam contra as políticas de classe média dominadas por grupos lésbicos/gays. O imperialismo é outro fator chave da politização das pessoas LGBTI. Mesmo a repressão, algumas vezes intensa, experimentada pela população LGBTI em países como o Líbano e a Palestina não são suficientes para convencê-la a alinharse às forças "liberais" estadunidenses, israelenses e europeias que agridem suas nações.

A resistência queer assumirá formas muito diferentes em lugares e circunstâncias diversas. Nenhuma identidade ou corrente 
pode ou deve dominá-la. Deve haver espaço para pessoas que se autoidentificam como lésbicas, gays, bissexuais, trans, intersexuais ou queer, para anarquistas, ambientalistas, militantes social-democratas, feministas de esquerda, antirracistas e mais. Cada vez mais, todavia, o radicalismo queer está se definindo não apenas como antineoliberal, mas também como anticapitalista. Isto não implica subscrever a nenhum modelo de alternativa socialista, e menos ainda seguir a liderança de qualquer organização. Implica, antes, em um reconhecimento de que as políticas neoliberais não são simplesmente equivocadas, mas o resultado da lógica inerente de um capitalismo global em crise.

Para alcançar uma liberação completa, a política queer tem de derrotar os poderes políticos e econômicos. Movimentos sociais e de classe - como as lutas por assistência médica e trabalhistas - devem tornar-se queer para poder dar uma dimensão sexual à transformação societária. Ao mesmo tempo, movimentos queer autônomos precisam radicalizar seu ataque à homonormatividade. Os imperativos fundamentais de uma política sexual queer radical podem ser identificados em oposição a cinco características basilares da normalidade gay:

\begin{tabular}{|c|c|}
\hline $\begin{array}{c}\text { Normalidade gay } \\
\text { neoliberal }\end{array}$ & $\begin{array}{c}\text { Política sexual queer } \\
\text { radical }\end{array}$ \\
\hline $\begin{array}{c}\text { Minorias gays/lésbicas } \\
\text { estáveis }\end{array}$ & Embaralhar as fronteiras \\
\hline Conformidade de gênero & Subversão de gênero \\
\hline $\begin{array}{c}\text { Exclusão de gênero e de } \\
\text { outros queers }\end{array}$ & $\begin{array}{c}\text { Inclusão queer/liberação } \\
\text { trans }\end{array}$ \\
\hline Homonacionalismo & $\begin{array}{c}\text { Solidariedade global } \\
\text { e anti-racista }\end{array}$ \\
\hline Famílias homonormativas & Poliamor \\
\hline
\end{tabular}


Na ordem familiar predominante do capitalismo generificado, a grande maioria das crianças é criada por pelo menos um pai biológico, em famílias dirigidas por casais heterossexuais. A grande maioria das crianças LGBTI cresce nessas famílias. As vidas LGBTI nesta situação resultam de uma combinação variante de adaptação e de guetização. Para evitar isto, uma política queer radical deve vislumbrar um futuro além do binarismo gay/hétero.

Mesmo hoje, uma política queer radical pode começar a borrar os limites do binarismo. Queers radicais desafiam as fronteiras sociais entre gays e héteros, simplesmente agindo sexualmente em cenários heteronormativos - por exemplo, através de beijos de língua entre pessoas do mesmo sexo em bares de solteiros heterossexuais. Ao mesmo tempo, ser queer não implica necessariamente uma orientação sexual imutável. O desejo sexual e o comportamento são fluídos. Assim, a flexibilidade tática ao proclamar a identidade sexual, em oposição ao imperativo rígido de "sair do armário" para integrar uma minoria, pode ser uma outra maneira de embaralhar a lógica binária. Haneen Maikey ${ }^{8}$ tem dito que o objetivo do grupo palestino Al Qaws "não é construir pontes entre a comunidade LGBTI e a sociedade, mas nadar no mesmo rio para mudar juntos seu curso" (MAIKEY, 2012). Também em comunidades das minorias negras e imigrantes deve haver espaço tanto para atuar discretamente no interior das famílias e das comunidades existentes quanto para reivindicar uma identidade LGBTI pública.

Um segundo eixo da transformação queer é subverter o gênero, que estrutura a reprodução da família heteronormativa, dos produtores edocapitalismo. Obviamente, as mulheres es movimentos demulheres são agentes centrais deste projeto, com as lésbicas desempenhando um papel chave. Liberdade reprodutiva, como as feministas de esquerda

\footnotetext{
${ }^{8}$ Ativista palestina queer diretora da Al-Qaws (arco-íris, em árabe), organização social voltada à promoção da diversidade sexual e de gênero na Palestina. [N.T.]
} 
definiram a partir dos anos 1970, inclui autodeterminação sexual. As demandas das feministas de esquerda, tanto por melhores condições no trabalho assalariado quanto por uma maior valorização do trabalho de cuidado, podem convergir com os esforços LGBTIQ de construir lares e comunidades alternativos.

Questões trans, em particular, são cada vez mais centrais. Lutas pela proibição da discriminação baseada na identidade de gênero, acesso integral à livre escolha de tratamento médico, escolas e lares seguros e receptivos às/aos jovens trans, proteção na prisão contra estupro e outras formas de violência, banheiros seguros e pronomes neutros de gênero para aqueles que não se identificam nem como masculinos ou femininos, tudo isso é vital. Eles podem nos levar a um mundo onde o significado social das distinções de gênero é muito menor, e as diferenças de poder baseadas no gênero desaparecerá completamente.

Um quarto eixo da transformação queer é a solidariedade para além das divisões raciais e nacionais. Pessoas LGBTI no mundo de hoje tem convergido o suficiente para terem uma verdadeira comunhão, que é uma base objetiva para a solidariedade. Para anticapitalistas, a solidariedade repousa sobre o entendimento de que todas as pessoas oprimidas estão combatendo a mesma ordem global, que só pode ser derrotada através de uma luta unificada. Experiências amargas ensinaram que a unidade global, para não ser um mero disfarce do controle de europeus e norte-americanos brancos, precisa estar baseada na autonomia e na liderança de negros, de imigrantes e de pessoas dos países economicamente dominados. Ainda assim, um universalismo eurocêntrico pode ser efetivamente desafiado somente por uma forte aliança anti-imperialista.

Queers da esquerda radical tem, cada vez mais, assumido como prioridade a solidariedade com negros e imigrantes LGBTI. Judith Butler, em 2010, recusou o prêmio Civil Courage - oferecido a ela pelo Comitê do Christopher Street Day de Berlin - para manter distância da "conivência com o racismo, incluso o racismo antimuçulmano"

212 A normalidade gay e a transformação... 
(SCHULMAN, 2012, p. 128-129). Muitos queers em todo mundo estão apoiando a luta travada pelos queers palestinos pelo BDS (boicote, desinvestimento e sanções), contra a autolegitimação israelense através do destaque dado aos direitos lésbicos e gays em Israel ("pinkwashing"). O grupo libanês LGBTIQ HELEM participou, em 2003, das mobilizações libanesas contra a guerra do Iraque e, durante a invasão israelense do Líbano, em 2006, o centro comunitário LGBTIQ de Beirute tornou-se um dos pontos de apoio mais movimentados (MAKAREM, 2011, p. 107-109). Muitos africanos organizando-se contra leis anti-LGBTI têm, ao mesmo tempo, rejeitado o uso de tais leis como pretextos para cortes de auxílio, que desconsideram a agência de movimentos LGBTIQ africanos, alimentam retrocessos, reforçam o poder dos países doadores e ajudam a excluir pessoas LGBTIQ da sociedade civil mais ampla (NANA et. al., 2011).

Um quinto eixo da transformação queer é organizar as vidas domésticas de maneira que elas sejam mais livres, mais flexíveis e mais abertas à comunidade em geral. Uma tática - frequentemente a única disponível às pessoas trans - é formar ou integrar lares e comunidades alternativas de dissidentes sexuais, como as hijras do Sul Asiático, ou jovens que fugiram de casa em Nova Iorque. Outra tática preferida por muitos, especialmente em países dependentes onde as pessoas LGBTI frequentemente dependem de suas famílias de origem para sobreviverem, é infiltrar a convivência queer nas famílias existentes, procurando evitar rupturas completas. Exemplos incluem pais que convidam os namorados de seus filhos para morarem com eles, da China às townships sul-africanas, às favelas brasileiras. Finalmente, as discussões queer sobre a liberação sexual, focam-se cada vez mais na ideia do poliamor, em "relações íntimas e sexuais (geralmente duradouras) com múltiplos parceiros simultaneamente" (BARKER, 2012, p. 176).

Um projeto para queerizar a intimidade e a vida doméstica deve ser a matriz básica para os posicionamentos sobre as uniões legais entre pessoas do mesmo sexo. O desafio é demandar mudanças 
na legislação sobre uniões civis que questionem as desigualdades mais amplas, da qual o casamento é apenas uma parte. Isto significa, por exemplo, lutar por direitos de reprodução com assistência médica; por direitos parentais automáticos para todas as mulheres comães; pelo apoio às crianças da comunidade como um todo; pela dissociação entre paternidade biológica e direitos e responsabilidades da paternidade social; por direitos individuais de assistência médica, benefícios sociais ou residências legais para aqueles que não são casais.

Ao mesmo tempo, a transformação queer não pode ser meramente um projeto pessoal, pois ela demanda uma transformação social que as pessoas LGBTIQ não podem fazer por conta própria. Queers precisam de aliados. Anti-capitalistas queer são naturalmente integrantes dos "99\%", dos movimentos como o Occupy e os indignad@s, que atuaram no enfrentamento da crise. Para serem aliados efetivos de uma política queer, movimentos sociais e de classe precisam ser queerizados: abrirem-se para pessoas queer, para lideranças queer, para questões queer e abordagens queer no processo de organização. Apenas movimentos que assumirem uma postura queer poderão enfrentar as necessidades LGBTIQ básicas como moradia para parceiros queer e segurança e independência para a juventude queer.

Movimentos em torno de assistência médica - do ACT UP ao South African Treatment Action Campaign (TAC) - têm sido casos exemplares de movimentos sociais que assumiram uma postura queer. O TAC apoiou-se em ligações anteriores entre ativismo LGBTI e anti-apartheid para obter acesso a medicamentos para HIV para sul-africanos pobres e de baixa renda. E tornou-se um ator central na luta contra as patentes de medicamentos nas mãos das multinacionais farmacêuticas.

Uma vez que a classe trabalhadora, em um sentido amplo, é indispensável à transformação social, o ativismo dos trabalhadores tem de assumir uma postura queer. Isto pode abranger a organização de questões relacionadas ao trabalho que ainda não são abordadas pelos sindicatos existentes - na indústria do sexo, por exemplo.

214 A normalidade gay e a transformação... 
A organização queer radical do trabalho demandará a rejeição do "economicismo asfixiante" da maioria dos sindicatos, e construir um "mundo social alternativo" com uma "cultura política transformadora" (HOLLIBAUGH e SINGH, 1999, p. 75, 80, 83).

\section{Construindo um futuro queer}

A verdadeira liberdade LGBTI necessariamente envolverá transformações completas que afetem todos os seres humanos. Especificamente, demandará o abandono do suposto papel fundante do sexo na determinação da sexualidade de cada indivíduo; uma transformação das unidades domésticas básicas, baseada na abolição do gênero como o conhecemos; uma superação da hierarquia global de nações e "raças"; e, mais uma vez, desafiar os parâmetros do capitalismo.

Hoje, como alternativa, sexualidades não-homonormativas frequentemente colocam um desafio, ao menos implicitamente, à reificação do desejo sexual que categorias como lésbicas, gays, bissexuais e héteros incorporam. O radicalismo queer precisa aprimorar este desafio e torná-lo explícito. Apenas dessa maneira podemos começar a criar as condições de possibilidade para a vida erótica com a qual há muito as pessoas sonham: polimorficamente sensual, ao invés de obcecada em genitálias, igualitária, ao invés de possessiva. Isto significa romper com o binarismo gay/hétero, de maneira que o desejo por pessoas do mesmo sexo se mescle com um universo mais amplo de desejo, que é bem recebido e compreendido em toda a sua diversidade e comunalidade [commonality].

Uma nova política queer radical demandará tanto a radicalização das massas LGBTIQ como também trazer boa parte dos queer radicais para uma concepção mais ampla de revolução social. Se a esquerda queer puder estar à altura desses desafios, poderá dar uma contribuição vital para o renascimento da esperança em um

cadernos cemarx, no $10-2017 \mid 215$ 
mundo que precisa desesperadamente dela - esperança de, finalmente, uma saída da crise e da violência, para um mundo de prazer generalizado e de uma liberdade genuína. A esquerda queer pode fazer com que a luta por esse mundo novo e melhor seja permanentemente inspirada pelo precioso amor entre camaradas.

\section{Referências bibliográficas}

BARKER, N. Not the Marrying Kind: A Feminist Critique of Same-Sex Marriage, Basingstoke: Palgrave Macmillan, 2012.

BROWNE, K. "By Partner We Mean...": Alternative Geographies of "Gay Marriage". Sexualities, v. 14, n. 1, 2011, p. 100-22.

D'EMILIO, J. The World Turned: Essays on Gay History, Politics, and Culture, Durham: Duke University Press, 2002.

. e FREEDMAN, E. B. Intimate Matters: A History of Sexuality in America, Chicago: University of Chicago Press, 1997.

DUGGAN, L. The New Homonormativity: The Sexual Politics of Neoliberalism. In:CASTRONOVO, R. eNELSON, D. Materializing democracy: toward a revitalized cultural politics. Londres: Duke University Press, 2002.

HOLLIBAUGH, A. e PAL SINGH, N. Sexuality, Labor, and the New Trade Unionism. Social Text, v. 17, n. 4, 1999, p. 73-88.

MAIKEY, H. Signposts from Al Qaws: A Decade of Building a Queer Palestinian Discourse, 2012. Disponível em: <http://www. bekhsoos.com/web/2012/05/alqaws/>.

216 A normalidade gay e a transformação... 
MAKAREM, G. The Story of HELEM. Journal of Middle East Women's Studies, v. 7, n. 3, 2011, p. 98-112.

NANA, J. G. et al. Statement of African Social Justice Activists on the Threats of the British Government to "Cut Aid" to African Countries that Violate the Rights of LGBTII People in Africa, 2011. Disponível em: <http://www.amsher.net/news/ViewArticle.aspx?id=1200>.

PEW RESEARCH CENTER. A Survey of LGBTI Americans: Attitudes, Experiences and Values in Changing Times, 2013. Disponível em: $<$ http://www.pewsocialtrends.org/2013/06/13/a-survey-ofLGBTI-americans/>.

PUAR, J. Terrorist Assemblages: Homonationalism in Queer Times, Durham, NC: Duke University Press, 2007.

RUBIN, G. Deviations: A Gayle Rubin Reader. Durham: Duke University Press, 2011.

SCHULMAN, S. Israel/Palestine and the Queer International, Durham: Duke University Press, 2012.

STRYKER, S. Transgender History. Berkeley: Seal Press, 2008.

WEEKS, J. The World We Have Won: The Remaking of Erotic and Intimate Life, London: Routledge, 2007.

WOLF, S. Sexuality and Socialism: History, Politics and Theory of LGBTI Liberation. Chicago: Haymarket Books, 2009.

WOLTERSDORFF, V. Paradoxes of Precarious Sexualities: Sexual Subcultures under Neo-liberalism. Cultural Studies, v. 25, n. 2, 2011, p. 164-82.

cadernos cemarx, no $10-2017 \mid 217$ 